Año LXXXI. urtea $276-2020$ Enero-abril Urtarrila-apirila

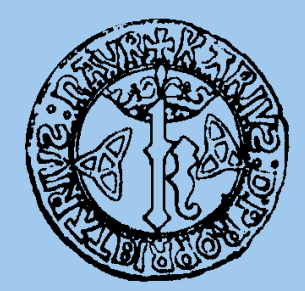

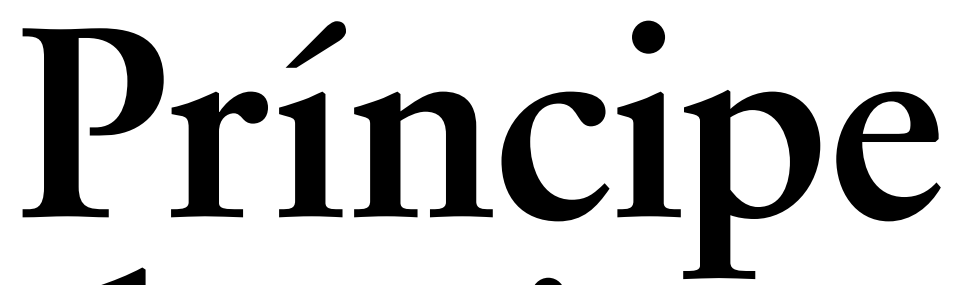
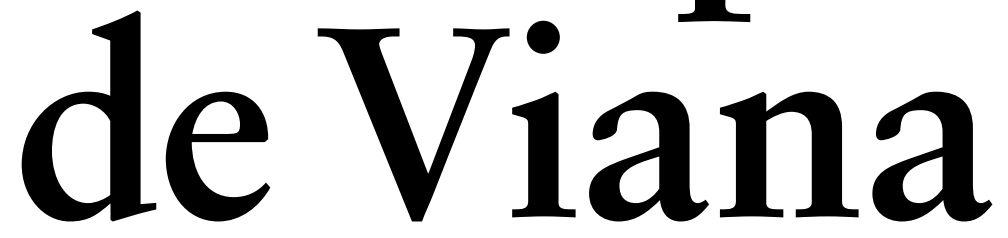

SEPARATA

Si mi padre volviera, yo sería su escudero. Qué gran caballero era

Tomás Yerro. (Discurso) 


\section{Sumario / Aurkibidea}

\section{Príncipe de Viana}

Año LXXXI • n. ${ }^{\circ} 276$ • enero-abril de 2020

LXXXI. urtea $\cdot 276$. zk. 2020 ko urtarrila-apirila

\section{LITERATURA}

La realidad literaturizada y la ira contra la religión católica y el obispo de Pamplona en el «Libro segundo» de La familia de Errotacho, de Pío Baroja Miguel Ángel García de Juan

\section{HISTORIA}

La represión del protestantismo en el tribunal inquisitorial de Calahorra-Logroño (1550-1610)

Marcos Gómez García

Entre España y México, la libertad. El embajador Félix Gordón Ordás y su evocación de la figura del navarro Javier Mina en el marco de la guerra civil española

Un discurso inédito de Víctor Sainz de Robles en 1867

Emilio Cervantes Ruiz de la Torre

Política social y autogobierno en el núcleo de la conspiración carlista antirrepublicana

La botica del monasterio cisterciense de Santa María de La Oliva (Navarra) Juan Manuel Garde Garde

\section{DERECHO / ZUZENBIDEA}

Un debate sobre la Ley de 1841: Navascués, la Diputación, «El Mosquerino» y Ezquerra 


\section{Sumario / Aurkibidea}

\section{LOS TRABAJOS Y LOS DÍAS DEL AÑO 2019 / 2019ko LANAK ETA EGUNAK}

Tesis doctorales sobre temática navarra de ciencias humanas, sociales y jurídicas, leídas en 2019

(Según la Base de datos Teseo del Ministerio de Educación)

Medio siglo de Fontes Linguae Vasconum

Ekaitz Santazilia

Actividades en torno al cincuenta aniversario de la revista Cuadernos de

Etnología y Etnografía de Navarra

David Mariezkurrena

Autores y autoras navarras en castellano, año 2019

Mikel Zuza Viniegra

Nafar egileen euskarazko liburuak 2019an

Ángel Erro Jiménez

Viento a favor: talento y carácter. Navarra en la industria audiovisual (2019)

Marga Gutiérrez Díez

Tensión de rotura. Un panorama expositivo de 2019

Mireya Martín Larumbe

Hiriartea: crónica de un proyecto frustrado por una mala práctica en las políticas culturales

Arantza Santesteban

De escalas, tiempos y cultura: grado en Historia y Patrimonio por la UPNA

Fernando Mendiola Gonzalo, Miguel R. Wilhelmi

Investigación y difusión del patrimonio cultural navarro en la Universidad de

Navarra (2019)

Yolanda Cagigas Ocejo

Entrevista a Tomás Yerro Villanueva. Premio Príncipe de Viana de la Cultura 2019

Alicia Ezker Calvo

Si mi padre volviera, yo sería su escudero. Qué gran caballero era

Tomás Yerro. (Discurso)

Currículums

Analytic Summary

Normas para la presentación de originales / Idazlanak aurkezteko arauak /

Rules for the submission of originals

6 Príncipe de Viana (PV), 276, urtarrila-apirila, 2020 ISSN: 0032-8472 | ISSN-e: 2530-5824 | ISSN-L: 0032-8472 


\title{
Si mi padre volviera, yo sería su escudero. Qué gran caballero era*
}

\author{
Tomás YerRo VilLANUEVA
}

DOI: https://doi.org/10.35462/pv.276.19

\section{Querido padre:}

«Se canta lo que se pierde», escribió don Antonio Machado. Hasta la fecha no me había puesto en comunicación directa contigo, pero desde que te fuiste, hace más de treinta años, no he dejado de pensar en ti ni un solo día. En situaciones de júbilo, rutina diaria y sobre todo de dificultad, me he venido preguntando cuál sería tu reacción: tu lenguaje corporal, tus certeras palabras, tus silencios sonoros. Hoy quiero confesarte algunas cosas que nunca te dije por pudor, falta de ocasión o quizás «la mala costumbre de querer a medias, / de no mostrar lo que sentimos a los que están cerca", como reza el poema de José Abraham cantado por Pastora Soler. A la mamá y a tu madre, la inolvidable abuela Javiera, dos pilares esenciales en la conformación de mi personalidad, ya tuve la oportunidad de expresarles en vida mis sentimientos.

De entrada, te voy a revelar sin rodeos algo para ti chocante: desde que yo era un crío hasta la actualidad, tú has sido mi mejor maestro. Y eso que nunca, nunca te vi leer un libro. Cuando echo la vista atrás, los recuerdos brotan a borbotones. Te observo en los ranchos con la familia y algunos vecinos junto a la presa del Regadío Mayor, donde descubrí tus dotes de cantante y bailarín. Y trabajando en la huerta de La Serna, tan cuidada como los jardines del palacio de Versalles. Y aquella tarde de mayo en que por primera vez te vi llorar: «iLo hemos perdido todo!», exclamaste después una pedregada histórica. Y tu paciencia cuando me indicabas la manera más adecuada de coger los

\footnotetext{
* Texto leído en el solemne acto de entrega del Premio Príncipe de Viana de la Cultura 2019, celebrado en la ciudad de Viana (Navarra) el 4 de mayo de 2019.
} 
espárragos, el «oro blanco» de la época. Y cuando nuestras dos hijas llegaban algunos domingos a vuestra casa y tú, el abuelo más feliz del mundo, las recibías con una sonrisa de oreja a oreja y ataviado con un traje azul que te sentaba de cine. Y tus comentarios sobre la Guerra Civil: "Aquello fue una salvajada que nunca debió pasar, en la que salimos perdiendo los de siempre, los que fuimos carne de cañón en ambos bandos». Y tu contagiosa animación en las fiestas patronales. Y tus dotes de mago para, durante un par de minutos, sostener el caldero recién sacado del fuego solo con la palma de tu curtida mano derecha a imitación de un camarero con bandeja de lujo. Y tu actitud serena al afrontar la enfermedad definitiva, más pendiente de los demás («lo mejor es no dar guerra, no estorbar», me decías) que de ti mismo. Para qué seguir.

Lo que más me encandiló de ti desde que tuve uso de razón fue la capacidad para hacer buenas migas con toda clase de gentes, sin distinciones. «Lo importante son las personas, no las ideas», te dejaste caer en una ocasión. En presencia de ti y de la abuela Javiera, me sentía acogido, arropado y acariciado por tu mirada azul; me hacías considerarme como un mocete y un joven importante, aunque no dijeras ni mu.

Sin pisar otra universidad que la escuela pública hasta los diez años, obtuviste matrículas de honor en asignaturas como el esfuerzo constante, la tarea bien hecha, la austeridad, la sencillez, la prudencia, la elegancia interior, la humildad, la palabra dada, la concordia, la bondad, la honradez, la gratitud, el compromiso social, la generosidad sin límites, la solidaridad con los más débiles y vulnerables... ¿Te acuerdas del mapa físico de España dibujado en colores por ti con primor en el curso 1928/1929 en las Escuelas Primo de Rivera, que, enmarcado y acristalado, adornaba una de las paredes de la cocina? Desde que aprendí a hablar me tiraba las horas muertas observando aquella obra y volviéndoos locos a mamá y a ti con preguntas, ahora lo reconozco, de muy difícil respuesta: «¿Cuántos litros de agua llevan todos los ríos a la vez? ¿Por qué no construyen un puente entre África y la Península? ¿Cuántas montañas hay en Navarra? ¿Por qué las islas Canarias aparecen debajo de las Baleares si decís que están situadas cerca de Marruecos, al Oeste de África?». Aquel cuadro fue, sin tú ni siquiera barruntarlo, el manantial del que brotó mi insaciable curiosidad intelectual.

Al terminar el segundo curso de bachillerato en Tudela, regresé a casa con unas notas muy brillantes. Mamá expresó su contento con felicitaciones entusiastas, besos y abrazos. Tú, más comedido y con la certeza de que mi destino no estaba en la agricultura, me dijiste a solas: «Tomás, eso está bien, pero no olvides nunca de dónde has salido». Padre, puedes estar seguro de que jamás he olvidado aquella recomendación. Es más, estoy convencido de que mi biografía se ha limitado a interpretar, con demasiada torpeza, eso sí, tu rica partitura vital: en las aulas, los despachos, las bibliotecas, las casas de cultura, los estudios de radio, los platós de televisión, los libros, las revistas, los periódicos, los centros cívicos, los clubes de jubilados, los asilos, los hospitales... He procurado trasladar a mi entorno los aromas inhalados en la familia, "esos días azules y este sol de la infancia», por decirlo de nuevo con el verso inolvidable de Antonio Machado. Con el anciano y admirado filósofo Emilio Lledó, siempre he creído que «No hay futuro sin memoria». En el fondo, no soy más que un chico de pueblo un poco ilustrado que siempre tuvo claro, como el gran poeta Rainer Maria Rilke, que «La verdadera patria del hombre es la infancia». 
El paso del tiempo acrecentó mi admiración hacia tu persona, fiel exponente de una generación de campesinos maltratada y vapuleada durante la guerra y la posguerra, víctima de unas condiciones políticas, sociales, culturales y económicas hoy intolerables. Aun así, los hombres y mujeres como tú fuisteis capaces de superar toda clase de obstáculos, de sacar a flote a vuestras familias con suma dignidad y muchos esfuerzos, y de ofrecer a vuestros hijos un porvenir más prometedor que el vuestro. Sin pretenderlo, fuisteis unos héroes sigilosos.

El aprendizaje realizado en nuestro domicilio en compañía de mis hermanos se enriqueció mucho en mi verdadera universidad de Harvard, que disponía de aulas abiertas a cualquier hora del día y de la noche: las casas, plazas, calles, río y campos de la villa de Lerín, repleta de historia. Mi amor por la lectura y la palabra surgió de la mano de la abuela, sí, pero sobre todo de la escucha embelesada del habla de los lerineses, caracterizada por un deje muy singular, y del hallazgo de vocablos como «desnietar», «desforrecinar», «acollar», «escalar» «edrar», «acarrear», «braván», «anchagarras», «cojona», «cunacho», «escolizarse», «gardacho», «hirmar», «mandorrotiar», «ruejo», «vulcar», «zaborra» y otros muchos. O términos municipales tan sonoros y sugerentes como Laguachal, Altamarigal, Cabizgordo, Frailía, Mondiuso, Recueja, Ribalva, Ripota, Saso, Sodillo, Sopeña, Subsierra, Tardana, Usón, Valseca y otros. Palabras precisas para designar un universo concreto, conocido por experiencia directa, nada que ver con muchos tópicos y clichés lingüísticos actuales, a veces interesadamente ambiguos o vacíos, profanadores del idioma español.

A satisfacer mi avidez cultural contribuyeron también estímulos tan variados como las muchas películas vistas en el Cine Parroquial y en el de El Chino. Las representaciones teatrales a las que asistí en el cine-teatro Avenida y en el Centro, donde me sobrecogió una función de Marcelino, pan y vino. Las numerosas «comedias» veraniegas en la plaza, que solían ofrecer espectáculos de variedades: canción española, bailes flamencos, actuaciones de payasos y algún número circense con acrobacias humanas y con animales. Seguro, papá, que todavía te sigue impresionando como a mí aquel hombre viejo y delgaducho sobre cuyo pecho, solo cubierto por un delgado paño, un mozo rompió con un mazo una piedra de Baigorri de cien kilos. Me deslumbraba la labor del pintor Emilio Sánchez Cayuela, Gutxi, manejando los pinceles en casa de sus parientes, los vecinos Gorricho, y con el caballete al aire libre. También, la música popular y sacra interpretada por Antonio Ramos, director de la Banda Municipal y organista de la parroquia de Nuestra Señora de la Asunción. En la iglesia, de trazas catedralicias, durante las festividades más solemnes se ofrecía una apoteosis de arquitectura, escultura, pintura, música, oratoria sagrada, liturgia espléndida y religiosidad, cifra y resumen del valioso patrimonio histórico-artístico local. No quiero robarte tiempo hablándote de nuestros juegos infantiles, pero conoces de sobra que el pórtico, la plaza Mayor, la Peña, el frontón, el fuerte, los porches, los Pinos, las Zorreras, las cuevas de la Virgen de la Blanca y el puente de La Cadena eran los escenarios predilectos de las aventuras y travesuras con los amigos. Unos sitios que favorecían la libertad de movimientos -vedada en nuestros días a los peques- y la imaginación.

Además, pronto empecé a darme cuenta de las diferencias e injusticias sociales, entre las que la generalizada falta de instrucción no era la menor. Nuestra familia era 
modesta, pero había muchas en situación más precaria. Para merendar, la mayoría de los chavales tomábamos un trozo de pan con una pastilla de chocolate, dieta que se completaba en la escuela con la leche en polvo y el queso americanos; otros tenían que conformarse con una rebanada empapada en vino. Mi condición de monaguillo me permitía acompañar a los curas para administrar la comunión de los primeros viernes del mes a los enfermos crónicos y la extremaunción a los moribundos. Puedes imaginarte, papá, la decrepitud y la dudosa higiene de no pocas viviendas. Por falta de recursos, muchas familias, varias de compañeros de pupitre, tuvieron que emigrar.

A edad muy temprana comprobé que algunos ancianos, empezando por la abuela Javiera y ciertos vecinos, poseían unas cualidades personales excelentes, aunque en general no se les hiciera demasiado caso. En mí suscitaban respeto y admiración, por lo que a menudo escuchaba sus conversaciones con fervor. Una vez hasta tuve el atrevimiento de sugerirte que le pidieras a tu madre que nos diera alguna clase en la escuela, propuesta que consideraste un disparate. Pero yo sabía lo que me decía: su forma de ser y sus conocimientos eran más preciados que los impartidos por ciertos maestros, a excepción de la hermana Asunción Cristóbal, que me enseñó a leer y escribir, y de la maestra doña Angelita, la sobrina del ilustre filólogo, profesor y crítico literario lerinés Amado Alonso, que me reveló con tanto rigor como cariño los intríngulis de la lengua.

Más adelante, a partir de los once años mi educación académica se completó, sobre una base sólida, en el Seminario Conciliar de Tudela y Pamplona y en la Universidad de Navarra. En el Seminario, productivo vivero de curas e institución educativa y cultural de primerísimo orden, a la que nuestra tierra todavía le debe un más que merecido reconocimiento público, tuve la suerte de contar durante el bachillerato con profesores tan magníficos como Martín Larráyoz, Juan María Lecea y Jesús Mauleón. En la Universidad me beneficié de la sabiduría y la cordialidad de lumbreras como Fernando González Ollé, Jesús Cañedo, Kurt Spang y Pedro Correa. La labor altruista de la bibliotecaria lerinesa Blanqui Celaya Hernández requeriría un capítulo aparte en el libro de los agradecimientos.

Papá, hoy tengo que darte una buena e inesperada noticia. Por iniciativa y tozudez de un grupo de hombres y mujeres navarros, todos escritores, por la propuesta de un grupo de sabios pertenecientes al llamado Consejo Navarro de Cultura y de las Artes y por la decisión del Gobierno de Navarra, se me ha concedido hace unos días el Premio Príncipe de Viana. Te explico de qué va el asunto. No te alarmes. Hablamos de un galardón que, dicen, «reconoce la trayectoria de personas o entidades relevantes en el mundo de la cultura». ¿Relevante? ¿Tú crees que es relevante haber hecho siempre, con gusto y naturalidad, aquello en lo que uno ha creído desde niño? Trayectoria relevante de verdad, pero en penumbra, ha sido la que escribisteis tú y mamá con la familia; relevantes han sido las biografías de tantas personas anónimas de Navarra que, en las administraciones públicas y en la sociedad civil, han dedicado y dedican sus mejores afanes a construir un mundo más habitable, quiero decir más sano, culto, libre, cohesionado, justo y solidario. Qué más da que sean maestros, profesores, escritores, técnicos de cultura, bibliotecarios, personal sanitario, científicos, transportistas, agricultores, voluntarios sociales, sindicalistas, políticos o gentes de bien en cualquier ámbito laboral. 
El próximo día 4 de mayo tendrá lugar la ceremonia oficial de entrega del premio en la histórica y hermosa localidad de Viana con asistencia de las máximas autoridades de la Comunidad Foral (en este caso, tú dirías: «habrá mucho baranda de por medio»), de una amplia representación de diversos estamentos sociales, educativos y culturales, de varios príncipes de la cultura, de un escogido puñado de amigos míos y de todos los miembros de nuestra familia, de la que estoy muy orgulloso: mi mujer, Pitina (el invisible timón de mi vida desde hace casi cincuenta años), mis dos hijas, mis yernos, mis cuatro nietos y mis tres hermanos con sus respectivas familias. Cuánto voy a echar de menos a mi amigo del alma Pablo Antoñana, vianés de pro, escritor fuera de serie y Príncipe de Viana de la Cultura desde 1996. Y además actuarán el Orfeón Pamplonés y la Orquesta Sinfónica de Navarra. Ahí es nada. El protocolo obliga a que el galardonado pronuncie unas palabras, tarea nada fácil ante un auditorio tan selecto.

Podría hablar, a ver qué te parece, papá, de mi concepción de la cultura, nada original por cierto, como un modo de vivir humanizado, asentado en valores de respeto, libertad, convivencia fértil, solidaridad y justicia, no en simple y estéril acumulación erudita de conocimientos o en mero espectáculo. Tampoco estaría mal llamar la atención sobre la necesidad de practicar la educación con un sentido intergeneracional, sin cortes bruscos ni saltos en el vacío: mirando siempre con esperanza al futuro, pero asentada en los mejores valores de la tradición clásica, digo yo. Aprovechando la presencia de políticos forales y municipales y la inminencia de elecciones autonómicas y locales, acaso valdría la pena hacer hincapié en la necesidad de mimar la educación y la cultura como aperos decisivos para cultivar las mejores potencialidades personales y lograr cohesión, transformación y progreso sociales, no división ni enfrentamiento. Puestos a pedir, tampoco estaría mal dar la tabarra sobre la urgencia de revalorizar las Humanidades y sus principios esenciales de justicia, verdad, bondad y belleza, cuya liquidación puede ser una de las causas principales de que el mundo se esté convirtiendo, poco a poco, en una selva intransitable.

Bueno, conforme vaya pensando mi discurso te iré consultando mis dudas. De momento solo estoy seguro de que será un privilegio, un placer y una verdadera fiesta proclamar mi más profunda gratitud, reconocimiento y alegría a cuantos han hecho posible el premio y al resto de candidatos; al Ayuntamiento de Viana, anfitrión; a mis antiguos profesores; a los numerosos hombres y mujeres que durante muchos años me han acompañado con respeto, confianza y afecto (entre otros, Guillermo Herrero, Javier Zubiaur, Javier Marcotegui y Pedro Burillo) en mis diversas actividades profesionales y de voluntariado social; a mis amigos más íntimos; a todas las gentes de Lerín, mi paraíso pasado y actual, y muy en especial a los miembros de mi cuadrilla, «La Revolución»; y, cómo no, a todos nuestros familiares. Y de manera muy singular a ti, Francisco Yerro Ona, Maestro con mayúscula, que ese día te harás más presente que nunca por ser el máximo acreedor al Premio Príncipe de Viana de la Cultura 2019.

Con un fuerte abrazo, tu hijo Tomás. 